\title{
Forecast of seismic resistance of structures by the results of numerical simulation of deformation properties of soil bases
}

\author{
Mikhail Sokolov*, Sergey Prostov, and Andrey Pokatilov \\ T.F. Gorbachev Kuzbass State Technical University, 650000, Kemerovo, 28 Vesennyaya st., Russian \\ Federation
}

\begin{abstract}
The object of the research is the forecast of seismic resistance when strengthening the soil foundations of structures. The purpose of the work is to numerically estimate the total increment of seismic intensity during artificial transformation and strengthening of foundation soils based on the results of geomechanical modeling. The study is based on classical mathematical methods for modeling soil foundations in a flat nonlinear setting. A new approach to determining the total increment of seismic intensity is presented, based on determining the ratio of the values of subsidence of the foundations of buildings and structures before and after soil strengthening. The paper presents the results of predicting changes in seismic resistance for real objects, obtained from the data of engineering and geological surveys and numerical computer models. It was found that due to the transformation of soil foundations, seismic resistance can decrease by more than 0.5 points. This technique can be used both to adjust the scoring for individual objects and to clarify the boundaries of seismic zones on OCP maps.
\end{abstract}

\section{Introduction}

The seismicity of Kuzbass has a mixed natural and technogenic character, while the number of weak seismic events continues to increase. The main reason for the growth of technogenic seismicity is the active development of minerals. There are 120 coal industry enterprises in the Kemerovo region, incl. 58 mines and 36 open-pit enterprises are in operation [1-5]. Until 2000, according to seismic zoning, Kuzbass was mainly related to the territory with seismicity of no more than 6 points, which did not provide for special anti-seismic measures during construction. According to the accepted standards, buildings are designed and constructed as seismic resistant in areas with a seismic hazard of 7 points and higher [6]. The overestimation of the seismic hazard of the region's territory has led to an increase in the region's score. The use of anti-seismic measures increases the cost of construction of

*Corresponding author: smv.ad@kuzstu.ru 
buildings and structures by an average of $30-40 \%$. The situation is complicated by the prevalence of weak watered soils, in the presence of which the seismicity increases by an additional point. The seismic impact on a building at a site with a seismicity of 7 points is 2 times higher than a 6-point impact, in turn, at 8-point sites, this impact is 2 times higher than a 7 point impact, and so on.

Reducing the seismic hazard coefficient is currently an important and urgent socioeconomic task. One way to do this is by compaction. To control the state of soil massifs, there are a number of physical and physicochemical methods aimed at transforming soil in order to increase its density; reducing porosity, strengthening the skeleton. On the territory of Kuzbass, the most promising are the methods of pressure injection of cement-sand mortars and electrochemical fixing $[7,8]$.

The design of strengthening soil foundations poses new challenges that are not available for classical analytical methods associated with the need to consider an anisotropic inhomogeneous foundation. The solution to this problem is the numerical computer modeling of the stress-strain state of soil massifs, in particular, based on the methods of numerical calculations. In this case, the local heterogeneous structure of the soil massif is taken into account quite accurately, which gives a more accurate idea of its deformations $[9,10]$.

\section{Research methodology}

In accordance with the normative documents [6], the seismicity of the construction area is determined by two values: the initial score determined from the OSR-1 or OSR-2 maps, and an additional increment of seismic intensity $\Delta I$, which depends on the differences in the physical and mechanical properties of soils in relation to to the conditions accepted as reference.

The value of $\Delta \mathrm{I}$ is determined by the method of seismic intensities $[11,12]$ :

$$
\Delta I=\Delta I_{2}+\Delta I_{B}
$$

where $\Delta I$ is the total increment of seismic intensity (in points) relative to the original point; $\Delta I_{g}$ is the increment in seismic intensity due to the difference in ground conditions, and $\Delta I_{w}$ is the increment in seismic intensity due to changes in the groundwater level.

The assessment of the difference in soil conditions is carried out according to the relationship between the acoustic and density properties of soils:

$$
\Delta I_{c}=1,67 \lg \left(\frac{V_{S \ni} \cdot \rho_{\ni}}{V_{\text {Sи }} \cdot \rho_{\mathrm{u}}}\right),
$$

where $V_{s e}, V_{s i}$ are the weighted average values of the shear wave propagation velocities in the reference and studied areas; $\rho_{e}, \rho_{i}$ - weighted average values of soil densities in the reference and studied areas.

The value of $\Delta \mathrm{Iv}$ is determined by:

$$
\Delta I_{B}=k \cdot e^{-0,04 h^{2}},
$$

where $k$ is a coefficient depending on soil conditions; $h$ is the position of the groundwater level, $\mathrm{m}$. 
Let us consider the possibility of changing the seismicity parameters by controlling the physical and mechanical properties of the soil foundations of structures using a complex of geotechnical methods.

A decrease in the value of $\Delta I_{6}$ is achieved by lowering the level of groundwater by methods of technical reclamation.

To assess the possibility of controlling the value of $\Delta I_{g}$, we use the equation for the velocity of transverse elastic vibrations

$$
V_{s}=\sqrt{\frac{E}{2 \cdot \rho(1+v)}}
$$

where $E$ is the deformation modulus, MPa; $v$ - Poisson's ratio, d.e $; \rho$ - density, $\mathrm{kg} / \mathrm{m}^{3}$. Substituting the magnitude of the velocities $V_{s}$ into equation (2), we obtain:

$$
\begin{array}{r}
\Delta I=\Delta I_{2}=1,67 \lg \left(\sqrt{\frac{E_{e} \cdot 2 \rho_{u}\left(1+v_{u}\right)}{2 \rho_{e}\left(1+v_{\ni}\right) \cdot E_{u}}} \cdot \frac{\rho_{e}}{\rho_{u}}\right) \\
=0,835 \lg \left(\frac{E_{e}}{E_{u}} \cdot \frac{1+v_{u}}{1+v_{\ni}} \cdot \frac{\rho_{e}}{\rho_{u}}\right) .
\end{array}
$$

The experience of geological and geophysical monitoring of the processes of improving the building properties of soils by the methods of pressure injection and electrochemical consolidation made it possible to establish the following [13]:

- an increase in the deformation properties of soils is provided to a large extent due to their compaction, and as a result of an increase in the rigidity of the soil skeleton, therefore, there is a relationship $\rho_{i}=\rho_{e} \cdot k_{l}$, where $k_{l}$ is the coefficient of soil compaction when filling the pores with a strengthening solution, $k_{l}=1.1-1.25=\mathrm{const}$;

- according to experimental data, in hardened soils there is no noticeable increase in the coefficient of transverse deformations, which means that $v_{i}=v_{e} \cdot k_{2}$, where $k_{2}$ is the coefficient taking into account the increase in transverse deformations, $k_{2}=1.1-1.15$;

- since after the impact on the soil base the load on it (pressure) did not change, and the size of the compressible base thickness is taken as the depth of deformation propagation, the ratio of the deformation module is inversely proportional to the ratio of the absolute values of displacements (subsidence).

Based on the above, equation (5) will have the form:

$$
\Delta I=\Delta I_{2}=0,835 \lg \left(\frac{S_{u}}{S_{\ni}} \cdot \frac{1}{K}\right),
$$

where $S_{i}, S_{e}$ are the subsidence of the base of the investigated and reference objects, respectively, $K$ is a constant that takes complex account of the values of the coefficients $k_{l}$ and $k_{2}$.

The parameters of the physical and mechanical properties of the soil base can be determined using geological and geophysical surveys, which require significant costs. However, with sufficient accuracy, surveys can be performed using mathematical models of the stress-strain state of the soil foundations of structures. It should be noted that this approach 
makes it possible to make a geomechanical forecast not only by the averaged parameters included in equation (6), but also by the weakest part of the soil base.

\section{Results}

The technique described above has been implemented at two construction sites. The all facet of technology of strengthening works, the results of engineering-geological surveys and modeling of the geomechanical state of the strengthened soil masses are presented in full in works $[14,15]$.

The territory of the first object is characterized by a planned relief, having absolute surface marks from 128.3 to $128.6 \mathrm{~m}$. The 5-storey structure has an L-shape in plan, with a maximum size of 53.0x40.4 m, with an exploited basement and a cold attic. The foundations of the building are concrete and rubble with varying depths of up to $4.9 \mathrm{~m}$.

According to engineering-geological surveys, a complex geological structure of the soil base was noted, including 4 main engineering-geological varieties of soils, presented in table 1. A feature of the structure of the soil base of the structure is the presence of watersaturated soil and inclusions with low deformation properties.

Table 1. Summary table of mechanical properties of geotechnical elements

\begin{tabular}{|c|c|c|c|c|c|c|c|}
\hline \multirow{2}{*}{$\#$} & \multirow{2}{*}{$\begin{array}{l}\text { Name of physical and } \\
\text { mechanical properties }\end{array}$} & \multirow{2}{*}{ Units } & \multicolumn{5}{|c|}{ geotechnical elements (GE) } \\
\hline & & & $\begin{array}{c}\text { GE - } \\
1\end{array}$ & $\begin{array}{c}\text { GE - } \\
2 \mathbf{a}\end{array}$ & $\begin{array}{c}\text { GE - } \\
2 \sigma\end{array}$ & $\begin{array}{c}\text { GE - } \\
3\end{array}$ & $\begin{array}{c}\text { GE - } \\
4\end{array}$ \\
\hline 1 & $\begin{array}{l}\text { Natural density } \rho \text { : } \\
\text { - in a natural state } \\
\text { - in a water-saturated } \\
\text { state }\end{array}$ & $\mathrm{g} / \mathrm{sm}^{3}$ & $\begin{array}{c}1,90 \\
-\end{array}$ & $\begin{array}{l}1,77 \\
1,87\end{array}$ & $\begin{array}{l}1,94 \\
1,79\end{array}$ & $\begin{array}{l}1,91 \\
1,88\end{array}$ & $\begin{array}{c}1,89 \\
-\end{array}$ \\
\hline 2 & $\begin{array}{l}\text { Internal friction angle } \varphi \text { : } \\
\text { - in a natural state } \\
\text { - in a water-saturated } \\
\text { state }\end{array}$ & deg. & $\begin{array}{c}18 \\
-\end{array}$ & $\begin{array}{l}14 \\
10\end{array}$ & $\begin{array}{l}17 \\
12\end{array}$ & $\begin{array}{l}13 \\
12\end{array}$ & $\begin{array}{c}13 \\
-\end{array}$ \\
\hline 3 & $\begin{array}{l}\text { Specific adhesion } C \text { : } \\
\text { - in a natural state } \\
\text { - in a water-saturated } \\
\text { state }\end{array}$ & $\mathrm{kPa}$ & $\begin{array}{c}10 \\
-\end{array}$ & $\begin{array}{l}23 \\
10\end{array}$ & $\begin{array}{l}30 \\
12\end{array}$ & $\begin{array}{l}17 \\
12\end{array}$ & $\begin{array}{c}15 \\
-\end{array}$ \\
\hline 4 & $\begin{array}{l}\text { Deformation modulus } E \text { : } \\
\text { - in a natural state } \\
\text { - in a water-saturated } \\
\text { state }\end{array}$ & $\mathrm{MPa}$ & $\begin{array}{c}15,0 \\
-\end{array}$ & $\begin{array}{c}11,2 \\
5,6\end{array}$ & $\begin{array}{l}23,0 \\
16,7\end{array}$ & $\begin{array}{l}9,0 \\
8,1\end{array}$ & $\begin{array}{l}7,4 \\
-\end{array}$ \\
\hline
\end{tabular}

As a result of the forecast of the geomechanical state of the soil base of this building, graphs of subsidence $\mathrm{S}$ of the soil base along the longitudinal axes of the northern and western facades of the building (see Fig. 1) were obtained for basic (Fig. 2, a, b) and local (Fig. 2, c) geomechanical models before and after work on soil consolidation. When model- 
ing the artificial massif, the fixing scheme developed by OOO NOOCENTR was taken into account (Fig. 2, d) [14].

$a$

$b$
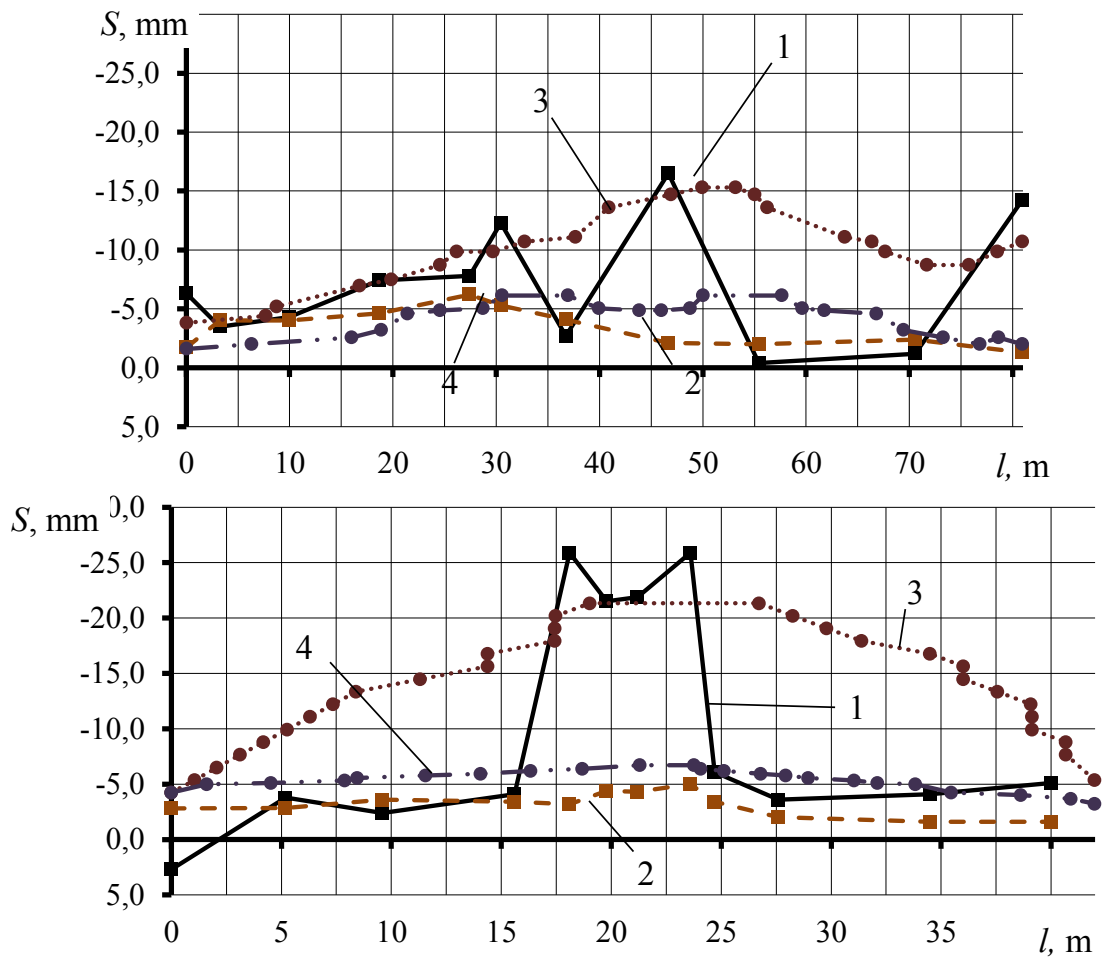

Fig. 1. Distribution of vertical subsidence $S$ along the longitudinal axes northern (a) and western (b) facades of the building: 1 - actual values before fixing; 2 - actual values after fastening; 3 - predicted before consolidation; 4 - predicted values after fixing

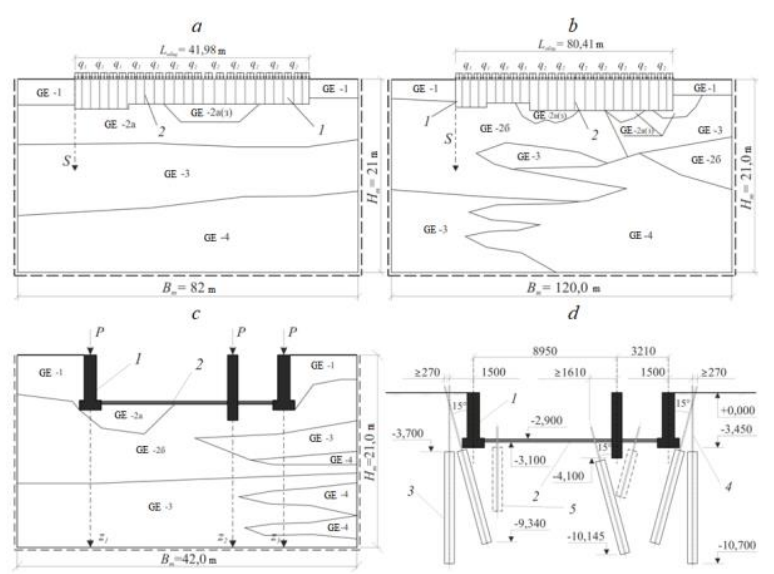


Fig. 2. Schemes of longitudinal basic models along the western (a) and northern (b) facades of the building, the transverse local model (c) and the scheme of fixing the foundation soils (d): 1 - foundation; 2 - basement floor; 3 - anchoring zone; 4 - injector; 5 - additional securing zones

The second object of the study was an administrative building, which is a complex of two combined buildings.

Engineering and geological surveys, the results of which are shown in Table 2, revealed the presence of subsiding loams and modern technogenic deposits, common throughout the site, with low physical and mechanical properties.

Table 1. Physical and mechanical properties of GE

\begin{tabular}{|c|c|c|c|c|c|c|c|c|}
\hline$\underbrace{0}_{\frac{011}{5}}$ & 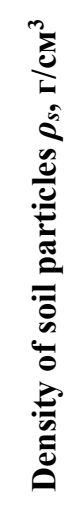 & 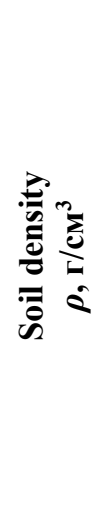 & 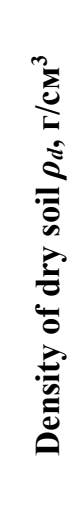 & 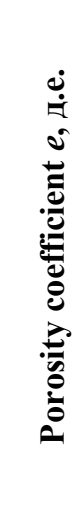 & 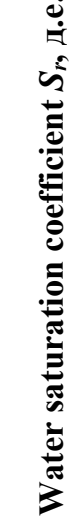 & 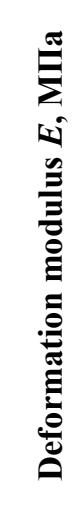 & 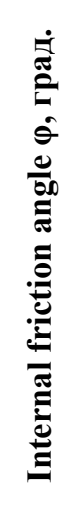 & 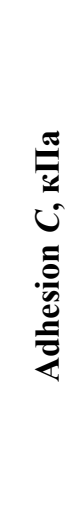 \\
\hline $4 a$ & 2,7 & 1,61 & 1,35 & 1,00 & 0,75 & 9,5 & 17 & 25 \\
\hline $4 \mathrm{~B}$ & 2,7 & 1,88 & 1,49 & 0,81 & 0,87 & 11,9 & 12 & 27,3 \\
\hline 5 & 2,7 & 1,81 & 1,50 & 0,79 & 0,7 & 24,1 & 22 & 23 \\
\hline
\end{tabular}

The conducted geomechanical forecast showed that the subsidence of the heterogeneous soil base is most pronounced in the zones of technogenic deposits ( $\mathrm{x}=4.5-7.5 \mathrm{~m})$ (Fig. 3).

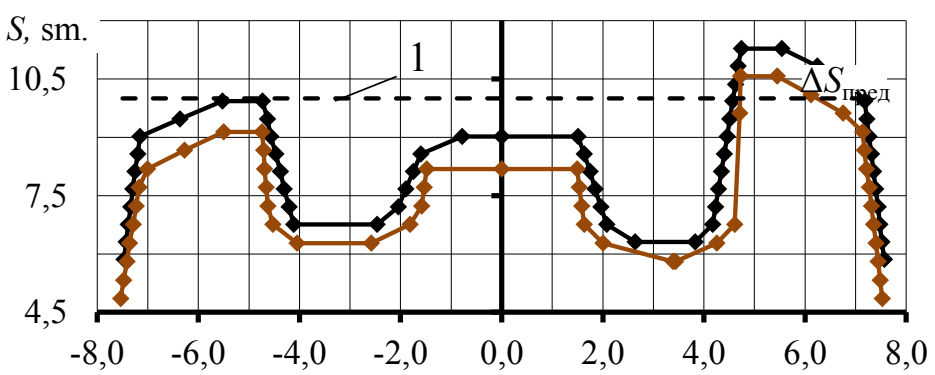

$x, m$

Fig. 3. Dependences of the distribution of vertical subsidence $S$ along the transverse axis x: 1 - in a natural massif; 2 - in an artificial array; $\Delta S_{l i m}$ - maximum permissible subsidence, according to [15] 
The presented results were obtained on computer models of a natural soil foundation (Fig. 4), as well as as a result of its strengthening according to a specially developed fixing scheme (Fig. 5).

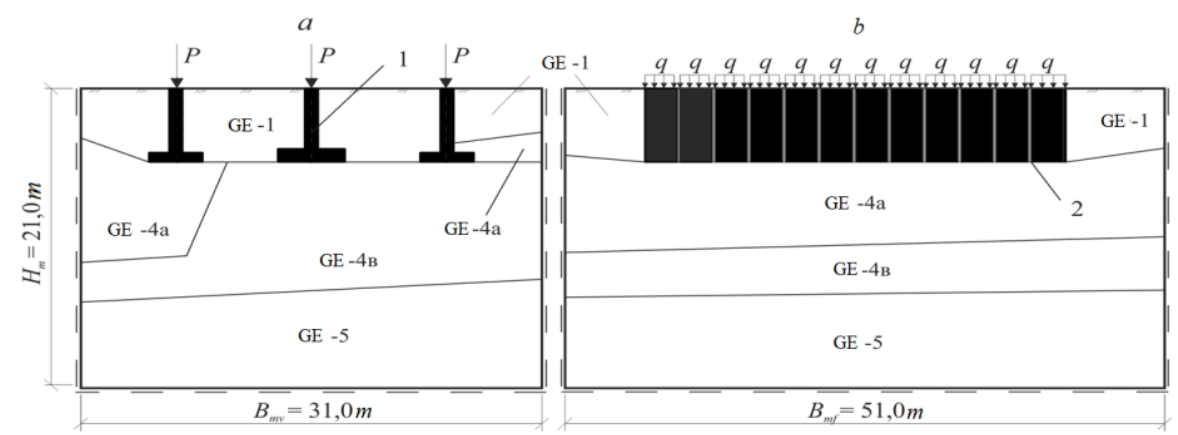

Fig 4. Scheme of basic models in the transverse (a) and longitudinal (b) profiles of the building: 1 foundation; 2 - deformation seam

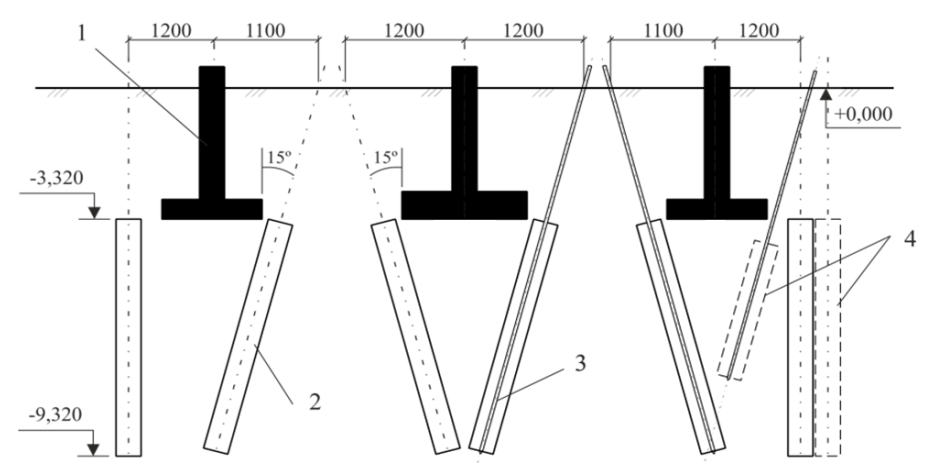

Fig. 5. Scheme of fixing the foundation soils in cross-section: 1 - foundation; 2 - anchoring zone; 3 injector; 4 - additional injectors

For the objects presented, an analysis of the influence of technogenic transformation of the soil base on seismicity was carried out, based on the method described above. The results of geomechanical prediction at $K=1.2$ are presented in table 3 .

Table 3. Analysis results

\begin{tabular}{|c|c|c|c|}
\hline $\begin{array}{c}\text { The value of } \\
\text { the } \\
\text { Object } \\
\text { name }\end{array}$ & $\begin{array}{c}\text { subsidence of } \\
\text { the soil base } \\
\text { before } \\
\text { consolidation, } \\
\text { The value } \\
\text { of the } \\
\text { subsidence } \\
\text { of the soil } \\
\text { base after } \\
\text { fixing, sm. }\end{array}$ & $\begin{array}{c}\text { The } \\
\text { magnitude } \\
\text { of the } \\
\text { increment } \\
\text { in seismic } \\
\text { intensity } \\
\text { due to the } \\
\text { difference } \\
\text { in soil } \\
\text { conditions }\end{array}$ \\
\hline \multicolumn{2}{|c|}{} & & \multicolumn{3}{|c|}{ According to the maximum values of settlements } \\
\hline
\end{tabular}




\begin{tabular}{|c|c|c|c|}
\hline $\begin{array}{c}\text { Object 1, } \\
\text { along the } \\
\text { western } \\
\text { facade }\end{array}$ & 21,34 & 5,946 & $-0,529516$ \\
\hline $\begin{array}{c}\text { Object 1, } \\
\text { along the } \\
\text { north } \\
\text { facade }\end{array}$ & 15,30 & 6,470 & $-0,378228$ \\
\hline Object 2 & 11,30 & 10,57 & $-0,090334$ \\
\hline \multicolumn{3}{|c|}{ According to the averaged values of subsidence } \\
\hline $\begin{array}{c}\text { Object 1, } \\
\text { along the } \\
\text { western } \\
\text { facade }\end{array}$ & 13,24 & 5,39 & $-0,392016$ \\
\hline $\begin{array}{c}\text { Object 1, } \\
\text { along the } \\
\text { north } \\
\text { facade }\end{array}$ & 10,25 & 4,20 & $-0,389658$ \\
\hline Object 2 & 8,11 & 7,27 & $-0,108175$ \\
\hline
\end{tabular}

\section{Conclusions}

1. Injection strengthening of soil foundations of structures in the presence of decomposed and moisture-saturated zones provides a decrease in seismicity by more than 0.5 points at peak values of subsidence, and at averaged values of more than 0.3 points.

2 . The proposed method for assessing the seismicity of the territory according to the data of engineering-geological surveys and numerical modeling of the geomechanical state of the massif under standard loads is advisable to use to clarify the boundaries of seismic zones on OCP maps.

\section{References}

1. D.V. Yakovlev, T.I. Lazarevich, S.V., Tsirel, Physical and technical problems of mining, 6, 20 (2013)

2. A.A. Bryksin, V.S. Seleznev, Geology and geophysics, 3:3, 399 (2012)

3. T.I. Lazarevich, A.N. Polyakov, Mining geomechanics and mark-shading business, $\mathrm{SPb}, \mathrm{VNIMI}, 40$ (2009)

4. Yu.A. Masaev, Bulletin of the scientific center for the safety of work in the coal industry, 4, 48 (2016)

5. A.F. Emanov et al., Physical mesomechanics, 12, 37 (2009)

6. SP 14.13330.2014. Construction in seismic regions SNiP II-7-81, M, Center for design production of FSUE (2018)

7. M.I. Ibragimov, V.V. Semkin, Fastening of soils by injection of cement mortars, 256, Moscow, ASV Publishing House (2012) 
8. S.M. Prostov, A.V. Pokatilov, D.I. Rudkovsky, Electrochemical soil consolidation, 294 (2011)

9. A.B. Fadeev, The finite element method in geomechanics, 221 (Moscow, Nedra, 1987)

10. S.G. Bezvolev, General method of calculating the stress-strain state of a soil massif with strengthening or weakening elements, Foundations, foundations and soil mechanics, 3, 16 (2008)

11. V.I. Bondarev et al., Recommendations for the use of seismic exploration for the study of physical and mechanical properties of loose soils in natural bedding for construction purposes, 142 (1974)

12. RSN 65-87 Engineering surveys for construction. Seismic microzoning. Technical requirements for the production of works, 26 (1987).

13. S.M. Prostov, V.A. Khyamalyaynen, O.V. Gerasimov, Complex monitoring of highpressure soil injection processes (2006)

14. M.V. Sokolov, S.M. Prostov, Bulletin of KuzGTU, 4, 5 (2017)

15. M.V. Sokolov, S.M. Prostov, Bulletin of KuzGTU, 3, 37 (2017)

16. Yu Huang, Miao Yu. Hazard Analysis of Seismic Soil Liquefaction, Springer Singapore, 165 (2017)

17. Dietlinde Kober, Mario De Stefano, Zbigniew Zembaty. Seismic Behaviour and Design of Irregular and Complex Civil Structures III. Springer International Publishing, 444 (2020) 